\title{
Effectiveness of Valsartan in Obese Versus Non-Obese Type 2 Diabetic patients presented with microalbuminuria
}

\author{
MUHAMMAD KASHIF KHAN ${ }^{1}$, SHAKEEL KHAN ${ }^{2}$, AHMAD SHAMIM KHA \\ KHALID ${ }^{6}$ \\ ${ }^{1}$ Consultant Nephrologist, Federal Government Polyclinic Islamabad \\ ${ }^{2}$ Senior Registrar Nephrology, Pakistan Institute of Medical Sciences Islamabad \\ ${ }^{3}$ Registrar Nephrology, Pakistan Institute of Medical Sciences Islamabad \\ ${ }^{4}$ Registrar Nephrology, Pakistan Institute of Medical Sciences Islamabad \\ ${ }^{5}$ Consultant Nephrologist, Federal government polyclinic Islamabad \\ ${ }^{6}$ Assistant Professor of Nephrology, Gujranwala Medical College Gujranwala \\ Correspondence to Dr. Khawar Sultan, Email: khawarthakur@gmail.com
}

\begin{abstract}
Aim: To ascertain efficacy of Valsartan, an angiotensin receptor blocker (ARB) in reducing microalbuminuria in obese verses non obese patients.

Methods: This comparative study was done in Department of Nephrology Pakistan Institute of Medical Sciences Islamabad from July 1, 2018 to December 31, 1018. Patients fulfilling selection criteria were enrolled and categorized as two groups obese \& non-obese; both groups were given valsartan. Urine ACR and serum creatinine was followed every month for 6 months.

Results: Average age of all cases as $52.06 \pm 4.11$ years while the mean age in obese and non-obese cases was $52.48 \pm 4.25$ years and $51.63 \pm 3.95$ years, respectively. The mean change in Urine ACR (from baseline to $6^{\text {th }}$ months) in obese cases was $41.76 \pm 25.81$ and non-obese cases was $76.05 \pm 7.63$, p-value $<0.001$. In obese cases mean urine ACR at $1^{\text {st }}$ and $2^{\text {nd }}$ month was same from baseline, $p$-value $>0.05$ while at $3^{\text {rd }}, 4^{\text {th }}$ month was statistically lower as compare to baseline urine ACR, $p$ value $<0.05$. Moreover, in non-obese cases the mean urine ACR was statistically decreased at $1^{\text {st }}, 2^{\text {nd }}, 3^{\text {rd }}, 4^{\text {th }}, 5^{\text {th }}$ and $6^{\text {th }}$ month when compared with baseline, $p$-value $<0.001$. At $4^{\text {th }}$ month in obese cases none of the cases achieved ACR $<30$ while in non-obese cases $4(7.4 \%)$ cases achieved ACR $<30$ with significantly higher frequency in non-obese cases, $p$-value $<$ 0.05 . At $4^{\text {th }}$ month in obese cases $12(22.2 \%)$ cases achieved ACR $<30$ while in non-obese cases $31(57.4 \%)$ cases achieved ACR $<30$ with significantly higher frequency in non-obese cases, p-value $<0.001$. At $6^{\text {th }}$ month in obese cases $20(37 \%)$ cases achieved ACR $<30$ while in non-obese cases $41(75.9 \%)$ cases achieved ACR $<30$ with significantly higher frequency in nonobese cases, p-value $<0.001$
\end{abstract}

Conclusion: Valsartan is more effective in reducing microalbuminuria in non-obese patients as compared to obese patients. Keywords: Diabetes mellitus, obesity, microalbuminuria, Valsartan

\section{INTRODUCTION}

Diabetes is defined as metabolic disorders with hyperglycemia due to inability of body for proper secretion of insulin, action of insulin, or can involve both. The condition of chronic hyperglycemia associated with diabetes is related to damage that is long-term dysfunction, and organs failure, involving eyes, nerves, kidneys, blood vessels, heart. ${ }^{1}$

Because of the aging population and an increase in obesity and sedentary lifestyle, the prevalence of DM2 is growing, particularly in Asia. Economically, diabetes type 2 burden related to obesity is generally underestimated involving factors like literacy and socio-economic status. Asians have higher pre disposition for resistance to insulin at somewhat obesity of lesser degree and pronounces dysfunction in early insulin secretion ${ }^{2,3,5}$. According to strong evidence antihypertensive agents targeting RAS can slow down renal disease progression and give cardioprotection for Type 2 Diabetes patients and microalbuminuria ${ }^{5}$. Angiotensin II receptor blocker (ARB) can be used as an alternate of ACE inhibitor if one is not able to bear certain side effects of an ACE inhibitor, e.g., it can cause an irritating $\operatorname{cough}^{6,7,8}$. In ARB literature it is found that, Conversion of microalbuminuria to normoalbuminuria was $12.5-29 \% \%^{9,10}$. Microalbuminuria represents elevation of excretion of urinary albumin on subclinical level. It is associated with excretion rate for albumin as 30 to $300 \mathrm{mg} /$ day or ratio of albumin-creatinine $(\mathrm{mg} / \mathrm{gm})$ of $25-$ 250 for males \& 35-350 for females ${ }^{4}$. The presence of microalbuminuria leads to renal disease worsening and also diabetic nephropathy with CVD ${ }^{5}$. Almost 30\% DM2 patients suffer urine albumin level as abnormally high; almost $75 \%$ among those patients suffer microalbuminuria \& almost $25 \%$ suffer overt diabetic nephropathy ${ }^{11}$.

Received on 21-05-2021

Accepted on 27-09-2021
Microalbuminuria is directly related to CVD diseases and renal failure. Patients suffering with DM2 and hypertension, reduction in serum albumin level is noted ${ }^{5}$

Rationale of this study is to study the outcome of ARB (Valsartan) in obese versus non-obese diabetic type 2 patients suffering with microalbuminuria. This study evaluated the role of valsartan in obese type 2 diabetic patient in reduction of microalbuminuria compared to non obese type 2 diabetic patients and thus its long term renoprotective effects.

\section{MATERIAL AND METHODS}

After approval from Institutional Ethical Review Board this comparative study was conducted at the Department of Nephrology PIMS Islamabad from July 1, 2018 to December 31, 1018. Patients were enrolled by following selection criteria; Inclusion Criteria: Paitents of both gender with age $\geq 40$ years having type 2 DM with microalbuminura and good blood pressure control of $<140 / 90 \mathrm{mmHg}$ (with or without use of drugs), CKD upto stage 3 with $\mathrm{HbA} 1 \mathrm{c}$ upto $7 \%$ was included.

Exclusion Criteria: Patients having CKD stage 4, above, HbA1c $>7 \%$ were excluded. Microalbuminuria was defined as Urine ACR of $30-300 \mathrm{mg} / \mathrm{g}$, with at least 2 of 3 measurments over $2-3$ months. Then patients were divided into two groups depending upon BMl; obese $(\mathrm{BMI} \geq 30)$ and non-obese $(B M I \leq 29.9)$. Both groups were given valsartan. Urine Albumin creatinine ratio (ACR) and Serum creatinine was followed every month for 06 months.

The collected data was entered and analyzed through SPSS version 25. Quantitative variables like age, creatinine level was presented in form of mean \pm S.D. Qualitative variables like gender, doubling of creatinine level, ESRD and mortality was presented in form of frequency and percentage. Independent sample t-test was applied to compare proteinuria between obese and non-obese patients. P-value $\leq 0.05$ was taken as significant. 


\section{RESULTS}

The mean age of all cases was $52.06 \pm 4.11$ years while the mean age in obese and non-obese cases was $52.48 \pm 4.25$ years and $51.63 \pm 3.95$ years respectively. In this study there was equal male to female ratio i.e. $50 \%$ male and female in either group.

eGFR in both groups: The mean eGFR at 0 day in obese cases was $81 \pm 13.9$ and in non-obese was $90 \pm 16.4$, p-value 0.058 . At $6^{\text {th }}$ month the mean eGFR in obese cases was $67 \pm 10.2$ and in non-obese cases was $84 \pm 15.5$, p-value $<0.05$. The mean eGFR in non-obese cases was statistically higher as compared to obese cases after treatment, $p$-value $<0.05$. The mean Change (from baseline to $6^{\text {th }}$ months) in eGFR in obese and non-obese cases, however, was $14 \pm 20.0$ and $6 \pm 30$ respectively, $p$-value $=$ 0.07 which was not significant.

Urine ACR in both groups: At 0 day the mean urine ACR in obese cases was $113.54 \pm 13.82$ and in non-obese cases was $112.33 \pm 12.40, p$-value $=0.635$. At $1^{\text {st }}$ month of treatment, the mean urine ACR in obese cases was $112.97 \pm 32.73$ and in nonobese cases was $81.48 \pm 16.75$, p-value $<0.001$. The mean urine ACR at $2^{\text {nd }}$ month in obese cases was $105.13 \pm 33.59$ and non-obese cases was $69.43 \pm 18.71$, p-value $<0.001$. At $3^{\text {rd }}$ month the mean urine ACR in obese cases was $96.34 \pm 35.45$ and in non-obese cases was $57.70 \pm 19.10, p$-value $<0.001$. At $4^{\text {th }}$ month the mean urine ACR in obese and non-obese cases was $87.56 \pm 36.78$ and $47.00 \pm 18.74$ respectively, $p$-value $<0.001$. At $5^{\text {th }}$ month of treatment, the mean urine ACR in obese cases was $78.04 \pm 40.27$ and in non-obese cases was $36.81 \pm 18.28$, $\mathrm{p}$-value $<0.001$. At $6^{\text {th }}$ month the mean urine ACR in obese cases was $71.78 \pm 39.63$ and in non-obese cases $36.28 \pm 20.03$, $\mathrm{p}$-value $<0.001$. The mean urine ACR in non-obese cases was significantly lower as compare to obese cases at each follow ups, $p$-value $<0.05$. The mean change in Urine ACR (from baseline to $6^{\text {th }}$ months) in obese cases was $41.76 \pm 25.81$ and non-obese cases was $76.05 \pm 7.63$, p-value $<0.001$. Results are shown in Figure I and Table I.

Fig I: Comparison of urine ACR in both groups at each month of follow up

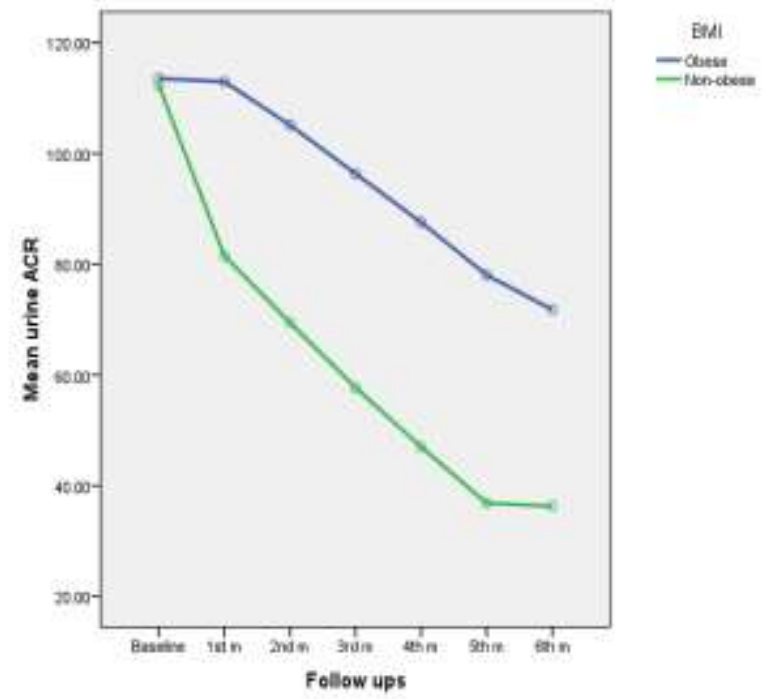

Table I: Comparison of ACR $<30$ in both groups at $6^{\text {th }}$ month

\begin{tabular}{|l|c|c|c|}
\hline \multirow{2}{*}{$\begin{array}{l}\text { ACR }<30 \text { at 6th } \\
\text { months }\end{array}$} & \multicolumn{2}{|c|}{ BMI } & \multirow{2}{*}{ Total } \\
\cline { 2 - 3 } & Obese & Non-obese & \\
\hline \multirow{2}{*}{ Yes } & 20 & 41 & 61 \\
\hline \multirow{2}{*}{ No } & $37.0 \%$ & $75.9 \%$ & $56.5 \%$ \\
\hline & 34 & 13 & 47 \\
\cline { 2 - 4 } & $63.0 \%$ & $24.1 \%$ & $43.5 \%$ \\
\hline
\end{tabular}

By the end of the study, $75.9 \%$ of the non-obese patients had achieved $A C R<30$ compared to only $37 \%$ of the obese patients.

\section{DISCUSSION}

High prevalence of obesity is increasing diabetes incidence; since both are interlinked for ESRD development, dissecting out individual chances of these is a difficult task. Considering pathophysiology of diabetic nephropathy and renal disease related to obesity are almost similar, both have raised initial glomerular filtration rate and intraglomerular capillary pressure, microalbuminuria and glomerular hypertrophy ${ }^{12}$.

Obesity is a major clinical burden globally as its prevalence is at an elevated level at present time and reaches much near to the proportion of epidemic $\left(B M I \geq 30 \mathrm{~kg} / \mathrm{m}^{2}\right)^{13}$. Many chronic disorders like type 2 diabetes, hypertension and cardiovascular diseases are main factors responsible for high obesity prevalence ${ }^{14}$. Obesity being closely linked to diabetes type 2, cardiovascular disease and hypertension, has worse health consequences like Chronic Kidney Disease (CKD) and End Stage Renal Disease (ESRD), and any one of these factors leads to increased risk for progression of these diseases ${ }^{15}$. There is strong evidence in literature showing that obesity elevates risk for ESRD independent diabetes type 2 and also for hypertension ${ }^{16}$. Obesity may cause CKD and ESRD development independently or may be related to diabetes type 2 \& hypertension contributes but the mechanisms related are not much understood. Major risk factors for ESRD are considered to be as diabetes type 2 \& hypertension, constituting $70 \%$ of total patients suffering with ESRD ${ }^{17}$.

A study reported that among diabetic cases there were $42.63 \%$ non-obese and $57.36 \%$ were obese with mean age was 55.9 years with $64.3 \%$ male and $35.7 \%$ female cases. ${ }^{18}$ In current study the average age of all cases as $52.06 \pm 4.11 \mathrm{yrs}$ that was almost similar to given study. We, by chance have both male and female cases with equal numbers.

The first choice of drugs for treatment of hypertension in diabetic patients are angiotensin-converting-enzyme inhibitors (ACEls) or angiotensin II receptor blockers (ARBs) due to the reduction in macrovascular and microvascular complications and their positive metabolic effects, which are independent of BPlowering effects. ${ }^{19}$ In people with type 2 diabetes, microalbuminuria is a strong, independent risk factor for diabetic nephropathy and cardiovascular morbidity and mortality. ACE inhibitor therapy decreased the risk of microalbuminuria in hypertensive subjects with type 2 diabetes and normoalbuminuria by about $40 \%$. Available data suggest that angiotensin II receptor blockers (ARBs) might have a similar renoprotective effect and that this effect might be increased by combined ACE inhibitor therapy ${ }^{20}$.

Recently, one study was done in order to see if any benefit could be taken from telmisartan for progression of microalbuminuria among normotensive individuals. more patients were reported to revert the levels to normoalbuminuria (UACR $<30 \mathrm{mg} / \mathrm{g}$ creatinine) after using telmisartan as $15.5 \%$ in $40 \mathrm{mg}$ category, $19.6 \%$ in $80 \mathrm{mg}$ category, and $1.9 \%$ in placebo category. Moreover, no correlation was found in changes of blood pressure and UACR among the normotensive patients who were being given telmisartan. Also the side effects were similar in the two groups ${ }^{21}$. The findings are in agreement to findings in current study as we also found that the mean change in Urine ACR (from baseline to $6^{\text {th }}$ months) in obese cases was $41.76 \pm 25.81$ and non-obese cases was 76.05 \pm 7.63 , p-value $<0.001$. In current study we extended the comparison over their obesity and found it more effective in non obese patients compared to obese patients.

Another randomized, placebo controlled, multicenter, double blind trial conducted in 2003 aimed to see the antiprotienuric effect of losartan in normotensive cases having 
diabetes as well as microalbuminuria. Significantly high reduction of $25 \%$ was seen in rates of albumin excretion at week 5 after 50 $\mathrm{mg}$ dose of losartan and up to $34 \%$ was seen in coming 5 weeks at a dosage of $100 \mathrm{mg}^{22}$. Another study found higher percentage change in urea as found by Zandbergen et al., 2003 (cited above) as they reported UAER to be $56 \%$ after 24 weeks $(95 \% \mathrm{Cl}, 49.6-63.0)$ with valsartan and $92 \%$ with amlodipine $(95 \% \mathrm{Cl}, 81.7-103.7)$, hence reporting a statistically significant between group effect $(P<0.001)$, whereas, it was seen that valsartan had the same reduction in the levels of UAER among the two groups i.e. normotensive and hypertensive. Also normoalbuminuria became common after giving valsartan (29.9\% vs. $14.5 \%$ and $P=0.001)^{23}$.

Another study concluded that for same reduction of BP and achieved levels of BP, among the patients of diabetes and microalbuminuria including normotensive patients, UAER was most effectively reduced by valsartan which lowered UAER more effectively than compared to amlodipine. Moreover, another study assessed the impact of angiotensin II receptor antagonist irbesartan among patients having hypertension as well as diabetes 2 with microalbuminuria. In their study, 10 among the 194 individuals in the $300 \mathrm{mg}$ category making $5.2 \%$ and 19 individuals among the 195 individuals from $150 \mathrm{mg}$ category making up $9.7 \%$ achieved primary end point, vs. 30 among 201 individuals from placebo category making up 14.9\% ( $p$-value $<$ 0.001 and $p$-value $=0.08$ for respective groups $)^{24}$.

\section{CONCLUSION}

Valsartan is more effective in reducing microalbuminuria in nonobese patients as compared to obese patients. However, it is useful even in obese diabetic type 2 patients suffering from microalbuminuria as well as non-obese type 2 diabetics.

Conflict of interests: None

\section{REFERENCES}

1. American Diabetes Association. Diagnosis and classification of diabetes mellitus. Diabetes care. 2010;33(Suppl 1):S62.

2. Saisho Y. Obesity, type 2 diabetes and beta cell failure: An Asian perspective. J Mol Genet Med S. 2014;1:1747-0862.

3. Staimez LR, Weber MB, Narayan K, Oza-Frank R. A systematic review of overweight, obesity, and type 2 diabetes among Asian American subgroups. Curr Diabetes Rev. 2013;9(4):312-31.

4. Menne J, Izzo Jr JL, Ito $\mathrm{S}$, Januszewicz A, Katayama S, Chatzykirkou $\mathrm{C}$, et al. Prevention of microalbuminuria in patients with type 2 diabetes and hypertension. J Hypertens. 2012;30(4):811-8.

5. Wylie E, Satchell S. Diabetic nephropathy. Clin Med 2012;12(5):480-82.

6. Nakao N, Yoshimura A, Morita H, Takada M, Kayano T, Ideura T. RETRACTED: Combination treatment of angiotensin-II receptor blocker and angiotensin-converting-enzyme inhibitor in nondiabetic renal disease (COOPERATE): a randomised controlled trial. Elsevier; 2003. p. 117-24

7. Cheng J, Zhang W, Zhang X, Han F, Li X, He X, et al. Effect of angiotensin-converting enzyme inhibitors and angiotensin I receptor blockers on all-cause mortality, cardiovascular deaths, and cardiovascular events in patients with diabetes mellitus: a meta-analysis. JAMA Int Med. 2014;174(5):773-85.

8. Vejakama $P$, Thakkinstian A, Lertrattananon D, Ingsathit A Ngarmukos C, Attia J. Reno-protective effects of renin-angiotensin system blockade in type 2 diabetic patients: a systematic review and network meta-analysis. Springer; 2012. p. 566-78.

9. Rossing $\mathrm{P}$, Parving $\mathrm{HH}$, de Zeeuw D. Renoprotection by blocking the RAAS in diabetic nephropathy-fact or fiction?. Nephrol Dial Transplant. 2006 Sep 1;21(9):2354-7.

10. Strippoli GF, Craig M, Deeks JJ, Schena FP, Craig JC. Effects of angiotensin converting enzyme inhibitors and angiotensin II receptor antagonists on mortality and renal outcomes in diabetic nephropathy: systematic review. BMJ. 2004;329(7470):1-11.

11. Ali A, lqbal F, Taj A, lqbal Z, Amin MJ, lqbal QZ. Prevalence of microvascular complications in newly diagnosed patients with type 2 diabetes. Pak J Med Sci. 2013;29(4):899-902.

12. Thomson SC, Vallon V, Blantz RC. Kidney function in early diabetes: the tubular hypothesis of glomerular filtration. Am J Physiol Renal Physiol. 2004;286(1):F8-F15.

13. Yanovski SZ, Yanovski JA. Obesity prevalence in the United States-up, down, or sideways? N Engl J Med. 2011;364(11):9879.

14. Flegal KM, Carroll MD, Ogden CL, Curtin LR. Prevalence and trends in obesity among US adults, 1999-2008. JAMA. 2010;303(3):235-41.

15. Foster MC, Hwang S-J, Larson MG, Lichtman JH, Parikh NI, Vasan $\mathrm{RS}$, et al. Overweight, obesity, and the development of stage 3 CKD: the Framingham Heart Study. Am J Kidney Dis. 2008;52(1):39-48.

16. Kramer H, Luke A, Bidani A, Cao G, Cooper R, McGee D. Obesity and prevalent and incident CKD: the Hypertension Detection and Follow-Up Program. Am J Kidney Dis. 2005;46(4):587-94.

17. De Zeeuw D, Ramijit D, Zhang Z, Ribeiro AB, Kurokawa K, Lash J, et al. Renal risk and renoprotection among ethnic groups with type 2 diabetic nephropathy: a post hoc analysis of RENAAL. Kidney Int. 2006;69(9):1675-82.

18. Matza LS, Yurgin N, Boye KS, Malley K, Shorr JM. Obese versus non-obese patients with type 2 diabetes: patient-reported outcomes and utility of weight change. Curr Med Res Opin. 2007;23(9):2051-62.

19. Kim HJ, Han SJ, Kim DJ, Jang HC, Lim S, Choi SH, et al. Effects of valsartan and amlodipine on oxidative stress in type 2 diabetic patients with hypertension: a randomized, multicenter study. Korean J Int Med. 2017;32(3):497-504. Epub 2016/12/30.

20. Ruggenenti P, Fassi A, llieva AP, Bruno S, lliev IP, Brusegan V, et al. Preventing microalbuminuria in type 2 diabetes. New Eng $\mathrm{J}$ Med. 2004;351(19):1941-51.

21. Makino $\mathrm{H}$, Haneda M, Babazono $\mathrm{T}$, Moriya $\mathrm{T}$, Ito $\mathrm{S}$, Iwamoto $\mathrm{Y}$, et al. Microalbuminuria reduction with telmisartan in normotensive and hypertensive Japanese patients with type 2 diabetes: a posthoc analysis of The Incipient to Overt: Angiotensin II Blocker, Telmisartan, Investigation on Type 2 Diabetic Nephropathy (INNOVATION) study. Hypertens Res. 2008;31(4):657-64.

22. Zandbergen AA, Baggen MG, Lamberts SW, Bootsma AH, de Zeeuw D, Rob JT. Effect of Losartan on Microalbuminuria in Normotensive Patients with Type 2 Diabetes MellitusA Randomized Clinical Trial. Ann Intern Med. 2003;139(2):90-6.

23. Viberti G, Wheeldon NM. Microalbuminuria reduction with valsartan in patients with type 2 diabetes mellitus. Circulation. 2002;106(6):672-8.

24. Parving $\mathrm{H}-\mathrm{H}$, Lehnert $\mathrm{H}$, Bröchner-Mortensen J, Gomis $\mathrm{R}$ Andersen S, Arner P. The effect of irbesartan on the development of diabetic nephropathy in patients with type 2 diabetes. $N$ Engl J Med. 2001;345(12):870-8 